DOI: https://doi.org/10.5007/1980-3532.2017n17p70

\title{
A abordagem de classe de Edward $P$. Thompson e sua aplicabilidade para estudos empresariais
}

\author{
The class approach of Edward P. Thompson and it's applicability \\ to entrepreneurial studies
}

\author{
Rodolfo Palazzo Dias \\ Universidade Federal de Santa Catarina \\ Doutorando em Sociologia Política \\ rodolfo.dias@gmail.com
}

\begin{abstract}
Resumo: O artigo desenvolve o conceito de classe de Edward P. Thompson, problematizando a sua operacionalidade especificamente para estudos empresariais no Brasil. A metodologia do "contextualismo linguístico" orientou a construção da pesquisa através do conceito de sentido: o processo mental realizado pelo autor ao desenvolver determinados conceitos. Pensar classe como "acontecimento", como dinâmica, permite: a) diferencia-lo do conceito de grupo (substância); b) destacar seu aspecto histórico, diacrônico; c) definir o papel da dialética no conteúdo do conceito; d) romper com definiçõos a priori do que se define como econômico, político e ideológico, problematizando como esses elementos interagem efetivamente na realidade. A importância do conceito de classe para a Ciência Política brasileira é tão grande quanto a dificuldade de operacionaliza-lo; definir as suas potencialidades, trabalho realizado aqui, é tarefa importante para orientar os que desejam observar as classes na realidade.
\end{abstract}

Palavras-chave: classes sociais; Edward P. Thompson; empresariado.

\begin{abstract}
The article develops the concept of class of Edward P. Thompson, problematizing its operability specifically for entrepreneurship studies in Brazil. The methodology of "linguistic contextualism" guided the building of the research through the concept of meaning: the mental process performed by the author in developing certain concepts. Thinking class as "event", as dynamic, allows: a) to differentiate it from the concept of group (substance); b) highlight its historical, diachronic aspect; c) define the role of dialectics in the content of the concept; d) to break with a priori definitions of what is defined as economic, political and ideological, problematizing how these elements effectively interact in reality. The importance of the concept of class for Brazilian Political Science is as great as the difficulty of operationalizing it; defining their potential, work done here, is an important task to guide those who wish to observe classes in reality.
\end{abstract}

Keywords: social classes; Edward P. Thompson; entrepreneurship.

Originais recebidos em: 18/09/2017

Aceito para publicação em: 20/04/2018

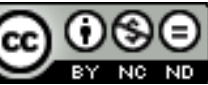

Comercial-Vedada a criação de obras derivadas 3.0 Unported Licens

Revista Em Debate (UFSC), Florianópolis, volume 17, p. 70-83, 2017. ISSNe 1980-3532 


\section{Apresentação}

O proposito do presente artigo é apresentar elementos teóricos desenvolvidos por Edward Palmer Thompson relacionados ao conceito de classe social que sejam úteis para uma pesquisa sobre empresários no Brasil.

Mesmo trabalhos com objetivos teóricos, se pretendem ter um enquadramento acadêmico, precisam seguir uma orientação metodológica. No presente trabalho não é adotado estritamente o "contextualismo linguístico" (SKINNER, 2005) porque os problemas são de ordem teórica (o texto de Thompson não será tratado enquanto objeto de estudo empírico). Porém, tal abordagem metodológica orienta no levantamento de certos debates como: o sentido de determinadas analogias feitas pelo autor (BIANCHI, 2014); e a propensão a interpretar os autores a partir da linguagem de sua época e para seus objetivos específicos.

O trabalho organiza-se com a seguinte estrutura: primeiro, o conceito de modelo em Thompson é apresentado, justificando o trabalho; segundo, são desenvolvidos os elementos conceituais de Thompson mais relevantes operacionalmente ${ }^{1}$; e terceiro, é desenvolvida uma reflexão sobre o pensamento de Thompson a respeito da economia, e, portanto, também sobre a aplicabilidade de suas considerações sobre classe para o empresariado.

O primeiro tópico inicia com uma questão fundamental: seria legítimo buscar uma definição de classe em um autor como Thompson? Justamente um autor que constantemente critica as categorias estabelecidas e também as suas próprias categorias; justamente um autor que se propõe fazer uma historiografia a partir de baixo.

\section{O "Modelo" em Thompson}

Respondendo a pergunta feita no último parágrafo, realmente os objetivos do presente artigos são "pouco thompsonianos". A grande quantidade de textos empíricos e a diminuta quantidade de textos teóricos; assim como a posição sempre crítica do autor diante das categorias estabelecidas; tais fatores tornam menos legítimo tentar precisar conceitualmente sua ideia de classe.

\footnotetext{
${ }^{1} \mathrm{O}$ foco é a operacionalização em estudos empresariais, campo empírico de análise bastante tradicional no Brasil, no qual o conceito de classe possui uma relevância significativa, e, como será mostrado ao final, também possui desafios importantes em sua aplicabilidade.

Revista Em Debate (UFSC), Florianópolis, volume 17, p. 70-83, 2017. ISSNe 1980-3532
} 
Mesmo assim, não considero tal objetivo incompatível epistemologicamente com o pensamento do autor. Busco sustentar tal argumento desenvolvendo as considerações de Thompson sobre o papel dos modelos dentro da análise histórica.

Um modelo, segundo Thompson, seria "uma metáfora do processo histórico, indicando suas partes significativas, a forma pela qual estão inter-relacionadas e a forma pela qual mudam." (THOMPSON, 2001, p. 154).

O primeiro elemento de destaque dos modelos é a sua "necessidade" para o historiador. Essa metáfora, que destaca certos acontecimentos e pressupõe suas interrelações, seria inevitável para o exercício da historiografia. A história possuiria dois lados segundo Thompson: um lado seria a história enquanto acontecimento, abrangendo tudo o que aconteceu; o outro seria a história tornando-se história através de modelos; ou seja, a série de eventos ocorridos tornam-se significados, passando por um processo social de padronização e explicitação. (THOMPSON, 2001, p. 155.) Esse processo de padronização seria a construção do modelo, que estaria implícito em qualquer exercício de interpretação e sistematização dos acontecimentos passados.

Mas como não interpretamos o passado senão com dados e métodos já desenvolvidos por outros, quando nos abstemos de utilizar os modelos de maneira clara não estamos pensando história sem modelos; estamos sim nos tornando "escravos de algum modelo escassamente conhecido de nós mesmos, lotado em alguma área inacessivel de preconceitos" (THOMPSON, 2001, p. 156).

Embora necessário, os modelos não são isentos de problemas. $\mathrm{O}$ segundo elemento dos modelos são os perigos inerentes a estes. O modelo corre o risco de petrificar-se em axiomas; ou seja, certa metáfora histórica, criada em um contexto, passa a ter aplicabilidade universal. A consequência de tal ato seria exigir de um contexto histórico específico as mesmas partes significativas e inter-relações semelhantes ao contexto que formulou o modelo, limitando a análise do período proposto $^{2}$. Além desse perigo, o direcionamento do olhar produzido pelo modelo pode levar ao descarte de certos fenômenos que possibilitariam a ressignificação daquele momento histórico.

É nesse equilíbrio entre necessidade e perigo dos modelos que surge o terceiro elemento dos modelos, sua potencialidade. Segundo Thompson (2001, p. 156-157), o

\footnotetext{
${ }^{2}$ Lembrar da crítica de Thompson a Perry Anderson, especificamente à sua análise da Revolução Inglesa. Revista Em Debate (UFSC), Florianópolis, volume 17, p. 70-83, 2017. ISSNe 1980-3532
} 
crescimento intelectual só ocorre dentro da tensão dialética produzida na disputa entre modelo e realidade.

A questão é, em vez disso, como utilizar um modelo com propriedade. A resposta, contudo, não é simples. Mesmo no momento de emprega-lo, o historiador precisa saber encará-lo com um ceticismo radical e manter-se aberto a respostas para evidências para as quais não tenha categorias (THOMPSON, 2001, p. 156).

A potencialidade analítica de certo conceito, portanto, estaria na sua forma de utilização. No presente trabalho não aplico diretamente o conceito de classe de Thompson ${ }^{3}$, e nesse sentido essa potencialidade analítica não é exercida. O objetivo é desenvolver um conceito de classe flexível o suficiente que, mesmo direcionando de olhar, permita uma leitura razoável dos acontecimentos históricos selecionados, assim como não seja totalmente refratário à fenômenos ou relações não destacadas a princípio.

\title{
Sobre o conceito de classe
}

Levando em consideração tais argumentos, é plausível desenvolver uma definição de classe baseada em contribuições do historiador inglês.

Muitos trechos de suas obras poderiam ser selecionados para tal finalidade. Mas me chamou a atenção um trecho d" "As peculiaridades dos Ingleses", primeiro, pelo fato de concentrar-se em elementos propriamente teóricos, e segundo, pelas analogias utilizadas.

\begin{abstract}
Os sociólogos que pararam a máquina do tempo e, com uma boa dose de pretensão e mau humor conceitual, desceram à casa de máquinas para dar uma boa olhadela nos contaram que em nenhuma parte puderam localizar e classificar uma classe. Apenas podem encontrar uma multidão de pessoas com diferentes profissões, rendas, hierarquias de status e tudo o mais. Decerto têm razão, uma vez que a classe não é esta ou aquela parte da máquina, mas a maneira pela qual a máquina trabalha uma vez colocada em movimento; não é este ou aquele interesse, mas a fricção de interesses - o próprio movimento, o calor, o ruído estrondoso. (THOMPSON, 2001, p.169).
\end{abstract}

Interrompo a citação nesse momento pois já é possível observar a analogia utilizada por Thompson em relação à física, primeiro fator de destaque. É difícil

\footnotetext{
${ }^{3}$ Essa aplicação, ou seja, a efetiva verificação da potencialidade analítica do conceito só pode ser feita em estudos empíricos práticos. O objetivo do artigo é oferecer um suporte conceitual para orientar futuros trabalhos empíricos sobre empresários, realizados tanto por mim como por outros acadêmicos. A efetiva cientificidade das propostas aqui apresentadas só poderá ser verificada a posteriori.
} 
estabelecer um objeto de estudo definido para a física ${ }^{4}$, mas é possível identificar que as analogias usadas por Thompson (movimento, calor, som) normalmente são objetos destacados da física, disciplina voltada a estudar o movimento e a dinâmica dos objetos; diferente da química, mais centrada na substância, na natureza dos objetos propriamente ditos.

É difícil definir o sentido (BIANCHI, 2014) dessa analogia em Thompson, ou seja, o papel que a analogia cumpre dentro do processo mental que Thompson realizou ao pensar classe. Mas é possível assumir como plausível que alguns elementos do significado dessas palavras tenham algo de comparável com o conceito de classe.

Diante dessa possibilidade, qual seria a utilidade da analogia da classe com a física? A diferenciando da química? Considero plausível assumir que a utilidade de tal analogia seria possibilitar a diferenciação dos conceitos de "classe" e "grupos" sociais. Da mesma maneiro que o calor, enquanto realidade (energia), não pode ser reduzida à vibração das partículas; também as classes não podem ser reduzidas à atributos de determinados grupos. Enquanto a classe evidencia a parte dinâmica da realidade social, os grupos evidenciam-na enquanto substância.

A classe enquanto movimento, enquanto dinâmica, atravessa a existência dos indivíduos componentes de uma determinada sociedade. Para complementar tal ideia seria interessante retomar um trecho do "18 brumário":

Os homens fazem a sua história; contudo, não a fazem de livre e espontânea
vontade, pois não são eles quem escolhem as circunstâncias sob as quais ela é
feita, mas estas lhes foram transmitidas assim como se encontram. A tradição
de todas as gerações passadas é como um pesadelo que comprime o cérebro
dos vivos. (MARX, 2011, p. 25).

Esta "tradição", ou o conjunto de "tradições" postos em movimento (e portanto em contradição), pré-existentes aos indivíduos, os situam dentro de determinada posição social. Isso não significa acabar com o papel da agência, afinal, como Marx destaca, são os homens que fazem a história ${ }^{6}$.

Os elementos conceituais de destaque a partir dessa analogia são: primeiro, em uma pesquisa empírica a distinção entre classe e grupo não deve implicar em uma

\footnotetext{
${ }^{4}$ Como Thomas Kuhn coloca (1998, p. 224), um paradigma se caracteriza primariamente como uma comunidade de cientistas, e não por um objeto de estudo. Embora nas ciências naturais a literatura produzida por tais autores demarca os limites dos objetos de estudo (KUHN, 1998, p. 220-221).

${ }^{5}$ Lembrando que Marx aqui também está trabalhando em termos analógicos.

${ }^{6}$ Ou como Thompson coloca: "Reduzir classe a uma identidade é esquecer exatamente onde repousa a agência, não na classe, mas nos homens” (THOMPSON, 2001, p. 171)
} 
exclusão de um ou outro conceito. Enquanto o conceito de classe se refere às disputas, interesses, posições, à luta propriamente dita; o conceito de grupo se refere ao comportamento, às decisões, à agência propriamente dita; e segundo, nem o comportamento pode ser deduzido imediatamente a partir da classe (interesses, disputas, etc.), nem as classes podem ser inferidas diretamente a partir de um grupo (a classe é uma realidade que atravessa os grupos). Os dois conceitos precisam ser distinguidos (pois são unidades analíticas distintas), porém, devem ser utilizados conjuntamente (cada um da conta de uma parte relevante da realidade social).

Agora, saindo da esfera da analogia e entrando no propriamente conceitual, continuo a citação anterior de Thompson:

Classe é uma formação social e cultural (frequentemente adquirindo
expressão institucional) que não pode ser definida abstrata ou isoladamente,
mas apenas em relação com outras classes; e, em última análise, a definição
só pode ser feita através do tempo, isto é, ação e reação, mudança e conflito.
Quando falamos de uma classe, estamos pensando em um corpo de pessoas,
definido sem grande precisão, compartilhando as mesmas categorias de
interesses, experiências sociais, tradição e sistema de valores, que tem a
disposição para se comportar como classe, para definir, a si próprio em suas
açães e em sua consciência em relação a outros grupos de pessoas, em termos
classistas. Mas classe, mesmo, não é uma coisa, é um acontecimento.
(THOMPSON, 2001, p. 169).

A última frase do seguinte trecho é o que fundamenta a validade da analogia com a física (e a crítica à substancialização da classe), assim como fornece uma base bastante precisa para desenvolver um conceito de classe: a classe seria um acontecimento!

Enquanto acontecimento, a classe não pode ser estudada estaticamente; não substância, mas sendo a dinâmica (movimento) o objeto de estudo ao qual se refere a classe, é necessidade intrínseca de tal gênero de estudo refletir em termos históricos. Como já destacava Thompson na "Formação da classe operária inglesa":

Se determos a história num determinado ponto, não há classes, mas simplesmente uma multidão de indivíduos com um amontoado de experiências. Mas se examinarmos esses homens durante um período adequado de mudanças sociais, observaremos padrões em suas relações, suas ideias e instituições. (THOMPSON, 2004, p. 11-12).

E quando fala em período adequado de tempo, Thompson reforça a importância da perspectiva em longa duração; para tornar-se o "fator mais significativo da política britânica”, foi necessário para a classe operária o período de 1780 até 1832 (THOMPSON, 2004, p. 12). 
A classe, portanto, para ser observada, tem que sê-lo em um intervalo temporal razoável. Mas em que direção o olhar deve ser lançado para observar esta classe? Percebe-se que um olhar direto para os sujeitos da história não é o suficiente. O perigo do voluntarismo ${ }^{7}$ seria constante nesse tipo de pesquisa. Mas nem por isso os atores devem ser abandonados (tanto a leitura do "18 brumário", como os textos empíricos de Thompson, mostram a importância dos atores no ato de analisar as classes).

Os atores precisam ser localizados em um contexto de disputa social. Os elementos que fazem parte desse contexto (ideias, cultura, organizações, instituições) não podem ser explicados apenas pelos atores, porque são derivados de um acumulo histórico mais longo, que atravessam gerações. Tais elementos também não são gestados de maneira isolada, mas sim em interação constante uns com os outros ${ }^{8}$. Essa interação possui um grau razoável de intensidade ${ }^{9}$, o que torna as relações entre as classes uma variável com um alcance social razoável. E, importante destaque para isso, essas interações ocorrem de maneira dialética.

Esse destaque é extremamente importante pois, ao definir essas relações como dialéticas, as relações de classes enquanto variável passam a assumir um significado específico. Distinta da "lógica formal", na qual as variáveis assumem identidades definidas (e portanto uma existência independente), na "dialética" (ou "logica dialética" definida por Henry Lefebvre) as variáveis expressam uma unidade entre identidade e diferença; seu entendimento passa pela sua colocação em relação a outras variáveis em contradição. E portanto sua existência é dependente em relação ao conjunto de outras variáveis, ou seja, dependente da totalidade (LEFEBVRE, 1975, p. 137-138). E o entendimento das variáveis e de suas relações (lógica dialética) reproduz de maneira semelhante os movimentos do próprio real.

Nesse sentido, o que está colocado não é apenas o problema da coesão e conflito. Dependendo do momento da luta, um grupo ou conjunto social pode decidir

\footnotetext{
${ }^{7}$ Ou, como Marx coloca, “um raio vindo de um céu sem nuvens” (2011, p. 18).

${ }^{8}$ É nesse momento em que ocorre o debate sobre os determinismos no marxismo. Nessa interação, quais seriam os elementos mais importantes? (os econômicos, no determinismo econômico). Quais seriam os mais poderosos? Os elementos mais importantes coincidem com os mais poderosos? Elementos de um mesmo setor interagem mais do que elementos de setores diferentes? (autonomia das instâncias). Consideramos que o capitalismo pode fornecer múltiplas respostas a tais perguntas, sendo elemento teórico mais as perguntas formuladas pelas abordagens do que suas respostas.

${ }^{9}$ Pensar a formação dos estados nacionais, a formação dos mercados nacionais e internacionais, a concentração populacional nas cidades, etc. Tais fatores produzem a intensidade de interações entre ideias e organizações que permitem a reflexão de uma formação social enquanto unidade. Permite conceber as relações de classes enquanto elemento explicativo de uma nação e das relações entre as nações.
}

Revista Em Debate (UFSC), Florianópolis, volume 17, p. 70-83, 2017. ISSNe 1980-3532 
pela aliança ou o combate, ambos influenciados pela mesma luta de classe. O que a contradição de classe significa é juntamente a divisão dos atores sociais em posições diferentes e desproporcionais, na qual a posição de um depende de uma dominação sobre outro. E o entendimento da existência de certa classe depende do tipo de relação que esta estabelece com a(s) outra(s).

É essa "lógica" de dominação que Thompson chama de "maneira como a máquina funciona". Ela é diferente de um ato de opressão: ela é resultado não de uma decisão individual, mas de um acúmulo de decisões passadas não diretamente relacionadas. Ela não impõe um comportamento (agência), mas limita a margem de possibilidade dos atores porque definem o próprio "ser"10 desses atores.

Portanto, se o objetivo é lançar um olhar sobre as classes, não deve-se olhar apenas para as decisões dos atores, mas também refletir sobre os condicionantes que estão envolvidos nessas decisões; na margem de possibilidades que existiam para a tomada dessas decisões. E para isso, não basta observar apenas a pressão oferecida pelos outros atores imediatamente postos na relação, mas temos que pensar nas instituições envolvidas, nas regras já estabelecidas, nas condições materiais dos atores, nas ideias e no sistema simbólico disponível para o ator e para seus opositores, etc. Tais fatores elencados, repetindo, não são fruto do acaso ou de condicionalidades imediatas, mas são resultado de um acúmulo histórico mais longo.

Mais do que indivíduos, pensar nas posições sociais ocupadas por estes, como essas posições também são ocupadas por um conjunto bastante amplo de indivíduos, e como esse compartilhamento de posições permite uma coordenação de comportamento classista (a classe influenciando o comportamento do grupo).

Como Thompson já deixa claro na sua citação, não existe uma grande precisão no momento de definir os componentes das classes, nem seus elementos (organizações, ideias, etc.). Isso precisa ser definido em cada estudo específico. Mas é justamente essa flexibilidade que dá ao conceito de classe a sua capacidade de pensar em termos históricos mais amplos. O que unificaria a análise da classe é justamente a lógica, a dominação (implícita ou explicita) na interação entre os atores dentro de um contexto social herdado.

\footnotetext{
10 "Ser" esse, que pela perspectiva histórica e diacrônica que estou assumindo, talvez fosse melhor definido como um "estar". Lembrando que Thompson é britânico, e que na língua inglesa as palavras "ser" e "estar" não são diferenciadas; as duas são compreendidas no verbo "to be".
} 
A análise de classe pensada enquanto modelo, enquanto metáfora, consistiria portanto na seleção de determinados atores, organizações, ideias, seguindo o critério da dominação posta em determinada formação social. Não seria a totalidade da história (todos os acontecimentos), mas representaria processos de longa duração.

\section{Considerações de Thompson sobre cultura e economia}

O grande tema de debate pelo qual Thompson é reconhecido são os temas de cultura. Colocando nos termos que foram desenvolvidos acima, isso significa que Thompson, ao lançar o olhar sobre determinada classe, busca identificar: como elementos culturais põem os atores em situação semelhante; opõe estes a outros atores; como as estratégias concretas dos atores (dos grupos, não das classes) buscam se adequar a cada situação de classe; e como tais estratégias possuem consequências de classe inteligíveis apenas para cada contexto de classe.

Esse foco nos estudos culturais pode ser encarado como um limitante para a incorporação do conceito de classe thompsoniano nos estudos empresariais; afinal, o conceito de classe do autor foi elaborado para dar conta somente da dimensão cultural?

Um argumento que desejasse responder afirmativamente à questão posta acima provavelmente iniciaria com a forte crítica de Thompson aos conceitos de base e superestrutura em Marx. Levantando a crítica thompsoniana à metáfora advinda da construção civil, que possuiria o problema intrínseco de excluir os atributos humanos do processo (THOMPSON, 2001, p. 158); tal argumento poderia caracterizar a forte ênfase de Thompson em relação à experiência como evidências do seu culturalismo, aproximando o autor erroneamente com o campo da filosofia do discurso (WOOD, 2010, p. 53-54).

Considero que as motivações de Thompson, ao negar a metáfora da base/superestrutura, não vem no sentido de negar a importância dos elementos econômicos nas relações capitalistas. O que motiva a crítica de Thompson à metáfora é o reducionismo, que seria "um lapso na lógica histórica por meio do qual eventos políticos ou culturais são 'explicados' em termos da afiliação de classe dos atores" (THOMPSON, 2001, p. 159).

Reducionismo esse que possuiria um extremo na ortodoxia stalinista enquanto determinismo causal da economia; e que possuiria outro extremo na não-determinação 
althusseriana, quando a economia é adiada para a imprevisível "última instância" (WOOD, 2010, p. 52). Nos dos casos, contudo, o papel da economia permanece obscuro.

O argumento de Thompson é que o próprio problema está mal colocado. Seria necessário produzir um modelo que se aproximasse mais das interações entre serconsciência $^{11}$ que ocorrem na realidade, e não uma separação arbitrária entre certos setores que contém elementos materiais, e outros que contém elementos abstratos.

E o ponto central da crítica à base/superestrutura é que não só as dimensões políticas e ideológicas possuem elementos de "ser", como também a dimensão econômica possui elementos de "consciência". Assim sendo, o problema do ser/consciência se coloca com a seguinte questão:

Pode algum modelo abarcar a dialética humana singular pela qual a história não aparece de maneira voluntariosa ou fortuita, nem determinada (...), nem ilógica (...)? (THOMPSON, 2001, p. 161).

A tendência desse momento do texto de Thompson seria negar a história como resultado puro e simples do comportamento dos agentes, ou como resultado puro e simples da lógica de funcionamento das organizações sociais.

Nesse sentido, é plausível concordar com Ellen Wood quando esta enfatiza: o fato de toda a atividade de produção material ser uma atividade consciente; com seu destaque na simultaneidade dos fenômenos ser-consciência; e também com o seu alerta de que não deveríamos cair em uma abordagem interacionista ou de dependência mútua, que significaria também tornar indefinido as relações entre ser e consciência (WOOD, 2010, p. 62-65).

Mas, ao negar a metáfora da base/superestrutura usada por Marx no prefácio de 1859, outra analogia, usada no mesmo texto, precisa ser debatida: "Não é a consciência dos homens que determina o seu ser, mas, ao contrário, é o seu ser social que determina a sua consciência” (MARX, 1982, p. 25). E qual seria o conteúdo dessa determinação?

Um estudo orientado pela metodologia do contextualismo linguístico exigiria o estudo da palavra "determina” no original (alemão) usado por Marx, assim como um

\footnotetext{
${ }^{11}$ Trabalho interessante sobre Thompson seria sobre seu conceito de consciência de classe, tendo em vista seu constante uso, mas diante de sua crítica às imagens antropomórficas usadas em muitos conceitos de classe (THOMPSON, 2001, p. 140). Não seria exigir demais da coesão ideológica de uma classe assumir um aspecto comparável à uma consciência? Como Thompson fornece elementos para essa crítica?
}

Revista Em Debate (UFSC), Florianópolis, volume 17, p. 70-83, 2017. ISSNe 1980-3532 
estudo aprofundado dessa palavra: o que ela significava em sua época? Quais são suas diferenças de significado quando aplicado em uma lógica causal e na dialética?

Este seria o procedimento mais adequado. Mas, pelas minhas próprias limitações, assim como pelos objetivos do artigo, apresento uma solução provisória (mesmo que arbitrária), tendo em vista a operacionalidade dos conceitos que estou desenvolvendo. Entendo o "ser social", primeiro, como um conceito mais abstrato, mais geral, e portanto, abarcando uma série de elementos da realidade (dentre elas a própria consciência). E segundo, considero a palavra determinação como se fosse delimitação; e que delimitar a consciência seria tanto em um sentido positivo (pôr oportunidades à disposição dos atores) como em um sentido negativo (pôr limites às escolhas desses atores).

A delimitação seria o movimento ${ }^{12}$ realizado pelo ser social em direção à consciência. Mas existiria o movimento contrário, de ação da consciência em direção ao ser social (em que medida a consciência também constitui o "ser" enquanto realidade). E para entender isso é interessante as passagens que Thompson extrai de Vico (2001, p. 161), que destaca: a) o papel da inteligência e das escolhas dos homens no processo histórico; b) mas o fato de os resultados de tais escolhas serem tão diversos das suas intencionalidades. Para retomar a frase de Marx no 18 brumário: os homens, suas decisões, fazem a história, portanto, são os elementos que, acumulados as longo de séculos em ideias e organizações, compõem a sociedade; mas é esse acúmulo, e não a decisão em si, que impõem limites e oferece oportunidades aos agentes do presente.

Não espero com isso resolver o problema do debate marxista sobre determinismo que ocorre a mais de um século. Pretendo formular apenas um conceito de classe viável para ser utilizado em um estudo sobre empresariado brasileiro.

\section{Conclusões}

Mas afinal, qual a necessidade desse debate teórico para o nosso objeto de estudo empírico? Sobre a literatura brasileira de empresariado, Sebastião Velasco e Cruz alerta:

$\mathrm{Na}$ leitura desses trabalhos, constitui experiência comum acompanhar análises que se iniciam ensaiando uma caracterização da elite do

\footnotetext{
${ }^{12}$ Movimento é apenas uma analogia. Lembrar da defesa de Ellen Wood em relação à simultaneidade.
} 
empresariado industrial e, sem elaborar minimamente a transição, terminam por qualificar a burguesia. (CRUZ, 1995, p. 22).

Essa dificuldade (transição) pode ser enfrentada com o debate teórico proposto acima através dos seguintes elementos:

1) Diferenciação de grupo e classe como unidades de análise de naturezas distintas (substância e dinâmica, respectivamente);

2) Negação da submissão de uma dessas unidades em relação à outra (a classe burguesa não pode ser observada através de um atributo específico de certo conjunto de empresários, nem o comportamento dos empresários pode ser deduzido apenas por sua posição de classe)

3) Os grupos interferem na dimensão de classe ao acumularem historicamente determinadas decisões (tomadas conscientemente) que se traduziram em elementos materiais, tornando-se partes do "ser" social ${ }^{13}$;

4) As classes interferem na dimensão dos grupos ao delimitarem a realidade na qual os grupos estão postos;

5) Os empresários, pela série de lutas que acumulam através da história, assumem condições determinadas em certos momentos; sua agência precisa ser compreendida por essas circunstâncias, mas o entendimento delas não substitui o efetivo estudo de suas ações.

6) A importância ou a força dos gêneros de elementos "econômico", "político" e "ideológico", assim como suas inter-relações, devem ser verificados na realidade histórica; servindo a literatura que debate o tema mais formuladores de boas hipóteses do que afirmações axiomáticas.

O presente artigo assumiu um caráter mais ensaístico do que o desejado. Gostaria de ter tornado mais preciso alguns conceitos aqui apenas mencionados; e também houve o uso demasiado de analogias. Mas mesmo tais fraquezas não se comparam à principal debilidade do texto: permanecer na discussão abstrata. $\mathrm{O}$ verdadeiro teste aos argumentos aqui estabelecidos é a aplicação dos conceitos em estudos de relações concretas de classe.

O momento histórico brasileiro torna esse estudo muito necessário, e um aparato conceitual adequado para faze-lo ainda mais imprescindível. Uma análise séria do

\footnotetext{
${ }^{13}$ Permaneço com o conceito mais usual dentro da literatura marxista, de "ser social". Mas que, diante de todos os desdobramentos teóricos até então desenvolvidos, poderia ser entendido como um "estar social", já que estamos trabalhando com processos históricos dialéticos de transformação.
} 
comportamento das camadas empresariais brasileiras diante dessa conjuntura de crise política presente no Brasil precisa abandonar uma análise meramente voluntarista ou unicamente estrutural.

O simples posicionamento das lideranças depende de um ambiente para sua eficácia, vide a capacidade de Paulo Skaf em coordenar os industriais para o objetivo político contra o PT, contrastada com a incapacidade de Katia Abreu de coordenar o setor agrário no sentido contrário. Mas nem por isso uma análise que busca uma "natureza conservadora" do empresariado brasileiro torna-se mais explicativa.

Deve-se observar, primeiro, os fracionamentos existentes dentro da classe; os acontecimentos relevantes que impactaram nas frações no médio e longo prazo (mudanças nas condições na década de 1990, o significado dos governos do PT para as diversas frações; o impacto desses eventos históricos nas instituições e na composição dessas frações); e a partir dai fazer uma análise das decisões concretas desses empresários, verificando os comportamentos mais e menos eficientes, e buscando uma explicação para o posicionamento relativamente coeso (o nível de coesão também é um elemento a ser estudado) da burguesia brasileira nos momentos mais críticos da crise política. A multiplicidade de posicionamentos existia, mas os mais eficientes foram capazes de direcionar a classe em determinado sentido histórico.

A abordagem aqui exposta poderia levantar o seguinte problema: qual classe burguesa "aconteceu" no período da crise de 2016 no Brasil? Tendo em vista a importância do tema, espero que as reflexões realizadas no presente texto colaborem, se não para uma resposta, ao menos para uma colocação mais correta das questões.

\section{Referências}

BIANCHI, A. Contextualizando Skinner. Trabalho apresentado ao IX Encontro da ABCP, Brasília. 2014.

CRUZ, S. C. V. Empresariado e Estado na transição brasileira: um estudo sobre a economia política do autoritarismo (1974-1977). Campinas: UNICAMP. 1995.

KUHN, T. S. A estrutura das revoluções científicas. ed. 5. São Paulo: Perspectiva. 1998.

LEFEBVRE, H. Lógica formal / lógica dialética. Rio de Janeiro: Civilização Brasileira, 1975. 
MARX, K. O 18 brumário de Luís Bonaparte. São Paulo: Boitempo. 2011.

Para a crítica da economia política. São Paulo: Abril Cultural. 1982.

SKINNER, Q. Significação e compreensão na história das ideias. In: Visões da política: questões metodológicas. Algés: DIFEL, 2005.

THOMPSON, E. P. A Formação da classe operária inglesa. v. 1. ed. 4. São Paulo: Paz e terra. 2004.

As Peculiaridades dos Ingleses e outros escritos. Campinas: Editora da Unicamp, 2001.

WOOD, Ellen Meiksins. Democracia contra o capitalismo: a renovação do materialismo histórico. São Paulo: Boitempo, 2003. 